\title{
Article \\ Stability of the Natural Joint Side in Unilateral Alloplastic Total Temporomandibular Joint Replacement Using a Ready-Made System
}

\author{
Jin-Hong Kim ${ }^{1} @$, Byung-Ho Park ${ }^{1}$, Myoung-Sang Yoo ${ }^{1}$ and Bu-Kyu Lee ${ }^{1,2,3, *}$ \\ 1 Department of Oral and Maxillofacial Surgery, Asan Medical Center, College of Medicine, \\ University of Ulsan, Seoul 05505, Korea; jinhong16@gmail.com (J.-H.K.); bhp1111@nate.com (B.-H.P.); \\ ryudaebak@naver.com (M.-S.Y.) \\ 2 Biomedical Engineering Research Center, Asan Institute for Life Sciences, Asan Medical Center, \\ College of Medicine, University of Ulsan, Seoul 05505, Korea \\ 3 Department of Stem Cell Center, Asan Institute for Life Science, Asan Medical Center, College of Medicine, \\ University of Ulsan, Seoul 05505, Korea \\ * Correspondence: bukyu.lee@gmail.com; Tel.: +82-2-3010-5907
}

check for updates

Citation: Kim, J.-H.; Park, B.-H.; Yoo, M.-S.; Lee, B.-K. Stability of the Natural Joint Side in Unilateral Alloplastic Total Temporomandibular Joint Replacement Using a Ready-Made System. Appl. Sci. 2021, 11, 3935. https://doi.org/10.3390/app11093935

Academic Editor: Seong-Gon Kim

Received: 17 March 2021

Accepted: 24 April 2021

Published: 27 April 2021

Publisher's Note: MDPI stays neutral with regard to jurisdictional claims in published maps and institutional affiliations.

Copyright: (c) 2021 by the authors. Licensee MDPI, Basel, Switzerland. This article is an open access article distributed under the terms and conditions of the Creative Commons Attribution (CC BY) license (https:// creativecommons.org/licenses/by/ $4.0 /)$.
Abstract: An alloplastic total joint replacement (TJR) is an effective and reliable treatment option in non-salvageable end-stage temporomandibular joint (TMJ) disease. However, unilateral alloplastic TJR of the TMJ (TMJ TJR) could affect the other side natural joint because the physiologic action of both condyles is quite different during mandibular movement. In this study, we examined whether the unilaterally replaced alloplastic TMJ TJR affects the other side natural joint condition over long periods of time. Eight patients who received alloplastic TJR on one side were subjects in this study. All alloplastic TJR implants were stable in situ. The average maximum mouth opening was $37.5 \mathrm{~mm}$ (range 19-49 $\mathrm{mm}$ ) pre-operatively and $44.1 \mathrm{~mm}$ (range 34-57 $\mathrm{mm}$ ) post-operatively. This parameter gradually increased and reached the maximum at about twelve months after surgery. The postoperative change of pain level was significantly reduced from 3.5 to 0 on a pain scale of zero to ten. No significant complications in any joints were observed within the follow-up period. The shape of the natural joint sides showed slight changes but were functionally stable during the observation period. In this study, unilateral alloplastic TJR showed stable and reliable clinical results, either alloplastic TJR or healthy joint sides for quite long period of time.

Keywords: temporomandibular joint disorders; total joint replacement; alloplastic reconstruction; follow-up studies

\section{Introduction}

The temporomandibular joint (TMJ) often loses its function due to various causes. In severe and non-salvageable cases, it often needs total joint replacement (TJR). Numerous procedures for TJR of the TMJ (TMJ TJR) are performed with either autologous or alloplastic materials with varying degrees of success $[1,2]$. The costochondral graft is popular as a conventional TMJ TJR procedure, which is standard in young patients [3-6]. Historically, alloplastic TJR has been an effective and reliable treatment option in orthopedic surgery $[7,8]$. For the TMJ, similar alloplastic TJR systems were introduced for the surgical management of end-stage TMJ diseases. Furthermore, recent evolution of imaging technologies have made this procedure more reliable and durable as a treatment option for restoring TMJ functions [9-11]. In the past, the use of alloplastic materials for TMJ TJR was avoided due to various foreign body reactions to the Vitek or Kent prostheses [12]. To overcome these problems, progressive approaches, such as the TMJ Concepts system and the Biomet Lorenz system, were developed and approved for TJR of TMJ by the Food and Drug Administration (FDA) in the United States. The Korean Ministry of Drug and Safety also approved the use of the Biomet Lorenz system for TMJ TJR. To date, this is the only approved system for 
TMJ TJR in Korea [13]. The Biomet Lorenz system is composed of a glenoid fossa and a ramus condylar component. The glenoid fossa component is formulated with ultra-high molecular weight polyethylene and the ramus condylar component is constructed from a cobalt-chromium-molybdenum alloy. The glenoid fossa component is fixed into the bony glenoid fossa with several positional titanium screws.

Clinical indications for TMJ TJR have been suggested and revised according to development of the system of TMJ TJR [14-16]. The success and longevity of an alloplastic TJR of the TMJ are directly attributed to stability in situ of the prostheses, biocompatibility of the prostheses, mechanical, and the reasonable indications of the surgery [17]. A predictable and satisfactory outcome of the reconstruction can only be expected under the appropriate diagnosis and indications.

Mandibular movement, as centered by the TMJ, is delicate and complex and can be only achieved by sophisticated and harmonious bilateral movement. Therefore, an unbalanced condition between the TMJs may cause harmful effects, resulting in degenerative changes in either joint. Different from the natural TMJ, the rotation center of an alloplastic TJR system is lower to compensate for the natural translational movement of the condyle, because it only allows rotational condyle movement. Lateral movement of the alloplastic TJR side is also limited, as the responsive muscles cannot attach to the artificial condyle and the condylar neck area.

Therefore, unilateral alloplastic TJR of TMJ may cause unexpected degenerative changes of the natural joint side and/or adverse effects of alloplastic joint side, because physiological actions at both condyles are quite different during mandibular movement. However, only a few studies have assessed the effects of unilateral TMJ total joint replacement. Franco et al. [18] and Perez et al. [19] evaluated patients requiring unilateral TMJ reconstruction with a patient-fitted total joint prosthesis and the risk for development of post-surgical contralateral TMJ pain and dysfunction leading to total joint reconstruction. Bekcioglu et al. [20] investigated stress distribution on the TMJ prosthesis and contralateral natural TMJ with finite-element analysis. These studies examined patient-customized prostheses for TJR of TMJ. Ready-made stock prostheses are generally affordable to patients rather than patient-customized ones although they provide limited sizes and shapes for correction of defects.

Thus, in this study, we examined under diverse clinical conditions whether unilaterally replaced alloplastic TMJ TJR using the Biomet system was reliable and whether it adversely affected the other natural joint side over time.

\section{Materials and Methods}

Criteria for study inclusion of the patients were those who have (1) inflammatory arthritis involving the TMJ that is not responsive to other treatments, (2) recurrent fibrosis and/or bony ankylosis not responsive to other modalities of treatment, (3) failed tissue grafts of bone and soft tissue, (4) failed alloplastic joint reconstruction, and/or (5) loss of vertical mandibular height, and/or (6) occlusal relationships because of trauma, pathologic bony resorption, or developmental abnormalities).

The patients who were subjected in this study were received unilateral alloplastic TMJ reconstruction with a ready-made TMJ stock prosthesis (Biomet TMJ Replacement System; Biomet Microfixation, Jacksonville, FL, USA) [21]. All surgical procedures were performed by a single skilled surgeon (B.K. Lee) at Asan Medical Center (Seoul, Korea) and all data were independently analyzed by three different doctors; and minimum three-year postsurgical follow-up. Standardized pre-surgical and post-surgical evaluation forms as approved by the institutional review board at Asan Medical Center (reference number S2020-0684-0001) were used to collect objective and subjective clinical data from patients.

According to our protocol, all patients were evaluated periodically based on maximum mouth opening (MMO), level of pain on a visual analogue scale (VAS) and any functional and physiological sequelae in both side joint conditions and occlusion. Both side 
joint conditions were also evaluated radiologically. Occlusal relationship was clinically evaluated for determining condylar stability of the TMJ.

On the alloplastic TJR side, any post-operative infection, implant displacement, and allergic response were observed. On the opposite natural joint side, any newly developed clinical symptoms, such as joint pain and noise, and condylar degenerative changes, such as absorption or erosion of condyle structures, were also monitored.

All surgical procedures of TMJ TJR with the Biomet system were consistently conducted by one skilled surgeon (Figure 1).
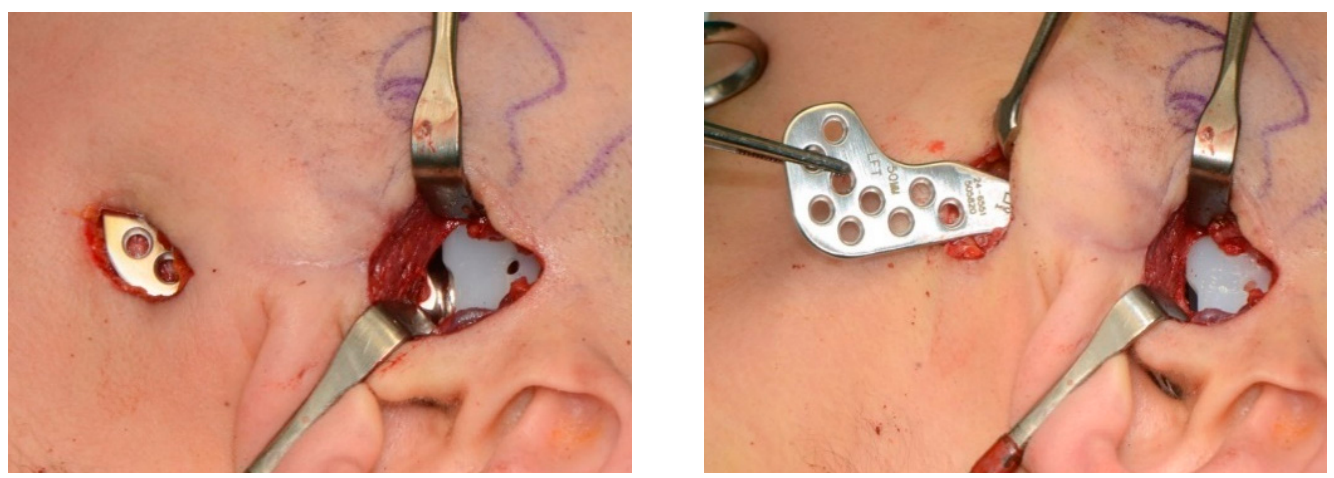

Figure 1. Surgical view for alloplastic total TMJ replacement.

For all patients, CT scans were taken pre-operatively for manufacturing 3D printed skull models (TAEGO Science Ltd., Seoul, Korea). To reduce total operation time and improve accuracy of the surgery, pre-surgical trial of fitting the artificial fossa and standard titanium condylar stem component (small, $45 \mathrm{~mm}$; medium, $50 \mathrm{~mm}$; large, $55 \mathrm{~mm}$ ) was conducted and the appropriated sized artificial fossa and condylar stem component were selected. In addition, bone grinding area for better fitting of the alloplastic TMJ components and inferior alveolar nerve location were also identified on the 3D printed patients' own skull model.

Surgery was done with standard technique in accordance with previously published reports [21-24].

The following post-operative protocol was instructed for all of the patients. There was no requirement for maxillomandibular fixation (MMF) post-operatively and active physiotherapy was commenced 5-7 days after surgery to first allow any pain and/or swelling to subside [21]. Briefly, the physiotherapy protocol was to perform maximal mouth opening exercise using patient's own fingers, 3 times in a row every set, and about 10 sets every $2-3 \mathrm{~h}$ a day. Patients were told to continue physiotherapy for at least 1 year and possibly longer.

On the next day after the operation, radiographs (panorama, cephalogram, CBCT scans) were taken to evaluate the position of the prosthesis and the natural condyle (Figure 2). For clinical evaluation, imaging was repeated at one month, six months, and three years after surgery. 

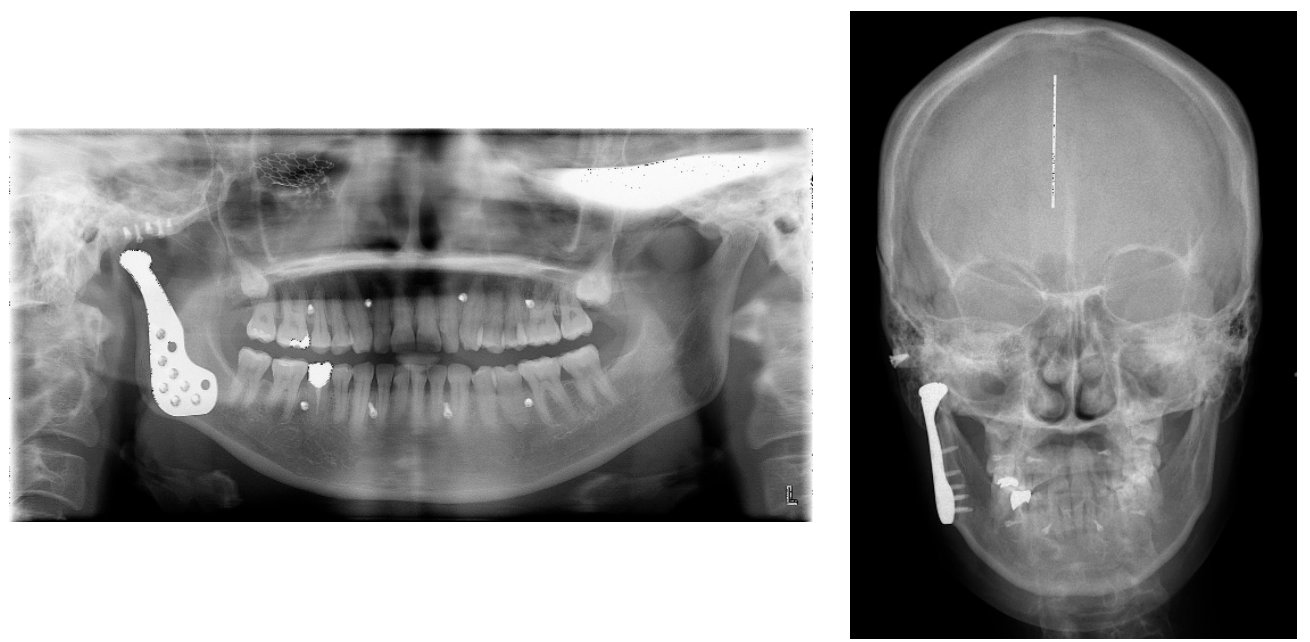

Figure 2. Representative post-operative radiographs at the first day after surgery.

\section{Results}

In total, eight patients (five male and three female patients) were included through our inclusion criteria for TMJ TJR. Patients' demographic features are summarized in Table 1. The mean age of the patients was 58.8 years (range $44-80$ years). Six patients (patient $1,3,4,5,7,8 ; 75 \%$ ) had poor outcome from previous operations. Another two patients (patient 2,$6 ; 25 \%$ ) did not received surgical therapy before, but patient's subjective discomfort and present illness (pain due to degenerative osteoarthritis and malocclusion due to trauma, respectively) fulfilled indication for surgery. Trauma was the major etiology, occurring 6 of 8 patients $(75 \%)$. Four patients had a malunited fracture of the mandibular condyle, and two patients had severe osteoarthritis and an open bite caused by condylar resorptions. One patient had total fibrous and bony ankylosis of the TMJ, and one patient had a fractured R-plate that was replaced after condylar mass removal. Relatively young patients (below 50 years; patient 4,7) were included in our study who appealed persisting discomfort even after previous conservative and surgical treatment. And there were patients who showed relatively low level of pain before surgery (below score of 5 ; patient $5,6,7,8$ ), but they suffered from serious malocclusion complaining chewing discomfort.

Table 1. Patient characteristics and diagnosis.

\begin{tabular}{|c|c|c|c|c|c|}
\hline Patient & Age & Gender & Operation Site & Diagnosis & $\begin{array}{l}\text { Previous Treatment } \\
\text { \& Present Illness }\end{array}$ \\
\hline 1 & 68 & M & Rt. & $\begin{array}{l}\text { (1) Malunion of Rt. condyle } \\
\text { (2) TMJ ankylosis \& osteoarthritis }\end{array}$ & $\begin{array}{l}\text { ORIF \& mouth opening } \\
\text { limitation }\end{array}$ \\
\hline 2 & 80 & M & Rt. & $\begin{array}{l}\text { Degenerative osteoarthritis } \\
\text { severe anatomical changes of Rt. condyle }\end{array}$ & $\begin{array}{l}\text { Severe erosion \& bony } \\
\text { ankylosis of condyle }\end{array}$ \\
\hline 3 & 62 & M & Lt. & Comminuted fracture of Lt. condyle & Closed reduction \\
\hline 4 & 44 & $\mathrm{~F}$ & Rt. & TMJ ankylosis of Rt. condyle & Arthroplasty \& Chronic pain \\
\hline 5 & 52 & M & Rt. & $\begin{array}{l}\text { (1) Osteochondroma of Rt. Condyle } \\
\text { (2) Fracture of R-plate }\end{array}$ & $\begin{array}{l}\text { Mass removal \& reconstruction } \\
\text { with rib bone and cartilage }\end{array}$ \\
\hline 6 & 57 & M & Rt. & Comminuted fracture of Rt. condyle & $\begin{array}{l}\text { Open bite \& mouth opening } \\
\text { limitation }\end{array}$ \\
\hline 7 & 44 & $\mathrm{~F}$ & Lt. & Comminuted fracture of Lt. condyle & $\begin{array}{l}\text { ORIF \& mouth opening } \\
\text { limitation }\end{array}$ \\
\hline 8 & 63 & $\mathrm{~F}$ & Lt. & $\begin{array}{l}\text { Osteoma with degenerative change of } \\
\text { Lt. condyle }\end{array}$ & $\begin{array}{l}\text { Biopsy (Osteoma) \& } \\
\text { malocclusion }\end{array}$ \\
\hline
\end{tabular}

Rt. = right; Lt. = left. 
Table 2 illustrates clinical outcomes and indicates the MMO before surgery and at six months and three years after surgery. The pain score is dictated on an analogue scale with 0 noted as 'no pain' and 10 as 'extremely painful', along with the score at each visit. Results show an increase in mandibular mouth opening from the pre-operative average of $37.5 \mathrm{~mm}$ (range $19-49 \mathrm{~mm}$ ) to the post-operative (at three years) average of $44.1 \mathrm{~mm}$ (range $34-57 \mathrm{~mm}$ ). The average pain visual analogue pain score (VAS score) was 3.5 (range $0-8$ ) pre-operatively, which decreased to an average VAS value of 0 post-operatively.

Table 2. Pre- and post-operative clinical outcomes: MMO, pain, and noise.

\begin{tabular}{|c|c|c|c|c|c|c|c|c|c|c|c|c|c|c|c|}
\hline \multirow{4}{*}{$\begin{array}{l}\text { Patient } \\
\text { Number }\end{array}$} & \multicolumn{3}{|c|}{ MMO (mm) } & \multicolumn{6}{|c|}{ Pain (VAS) } & \multicolumn{6}{|c|}{ Noise } \\
\hline & \multirow{3}{*}{ Pre-Op. } & \multicolumn{2}{|c|}{ Post-Op. } & \multirow{2}{*}{\multicolumn{2}{|c|}{ Pre-Op. }} & \multicolumn{4}{|c|}{ Post-Op. } & \multirow{2}{*}{\multicolumn{2}{|c|}{ Pre-Op. }} & \multicolumn{4}{|c|}{ Post-Op. } \\
\hline & & \multirow[t]{2}{*}{6 Months } & \multirow[t]{2}{*}{3 Years } & & & \multicolumn{2}{|c|}{6 Months } & \multicolumn{2}{|c|}{3 Years } & & & \multicolumn{2}{|c|}{6 Months } & \multicolumn{2}{|c|}{3 Years } \\
\hline & & & & A & $\mathbf{N}$ & A & $\mathbf{N}$ & A & $\mathbf{N}$ & A & $\mathbf{N}$ & A & $\mathbf{N}$ & A & $\mathbf{N}$ \\
\hline 1 & 19 & 40 & 44 & 8 & 0 & 2 & 0 & 0 & 0 & - & - & - & - & - & - \\
\hline 2 & 45 & 49 & 49 & 5 & 0 & 0 & 0 & 0 & 0 & + & - & - & - & - & - \\
\hline 3 & 40 & 50 & 57 & 5 & 0 & 0 & 0 & 0 & 0 & - & - & - & - & - & - \\
\hline 4 & 43 & 45 & 40 & 7 & 0 & 7 & 0 & 0 & 0 & + & - & - & - & - & - \\
\hline 5 & 38 & 38 & 39 & 0 & 0 & 0 & 0 & 0 & 0 & - & - & - & - & - & - \\
\hline 6 & 33 & 43 & 44 & 2 & 0 & 0 & 0 & 0 & 0 & - & - & - & - & - & - \\
\hline 7 & 33 & 36 & 34 & 1 & 0 & 0 & 0 & 0 & 0 & - & & - & - & - & - \\
\hline 8 & 49 & 44 & 46 & 0 & 0 & 0 & 0 & 0 & 0 & + & & - & - & - & - \\
\hline
\end{tabular}

$\mathrm{A}=$ alloplastic side of TMJ; $\mathrm{N}=$ natural side of TMJ.

The consistent tendencies of average MMO change and VAS score change are shown in Figure 3. The average MMO was $37.5 \mathrm{~mm}$ pre-operatively, and the last average MMO was $44.1 \mathrm{~mm}$ post-operatively. The average lateral excursion movement of the mandible was $1.3 \mathrm{~mm}$ to operated side and $7 \mathrm{~mm}$ to the natural joint side. The alterations of pain VAS scores during various follow-up visits were consistently decreased to 0 from 3.5. Between one month and three months after surgery, the range of mouth opening was increased. The greatest decrease in pain score was observed within one week after surgery.

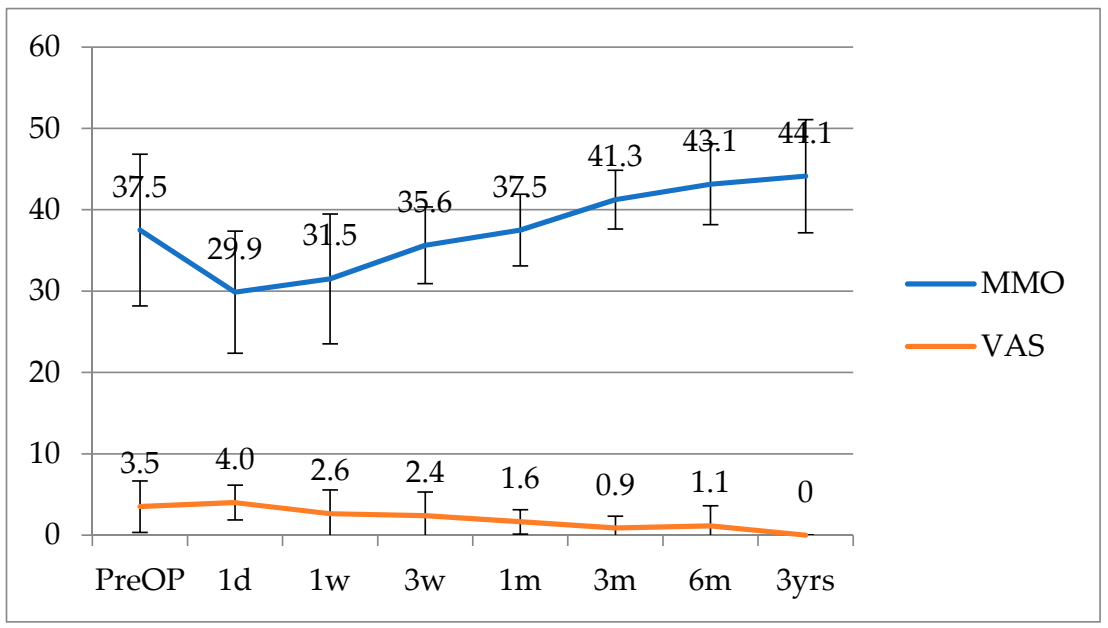

Figure 3. Consistent tendency of change in MMO and pain score (VAS).

No significant complications were observed by radiographic images and clinical exams in any operated joints within the follow-up periods. All natural joint sides were also stable and no functional disabilities were observed with minimal remodeling (Figure 4). 


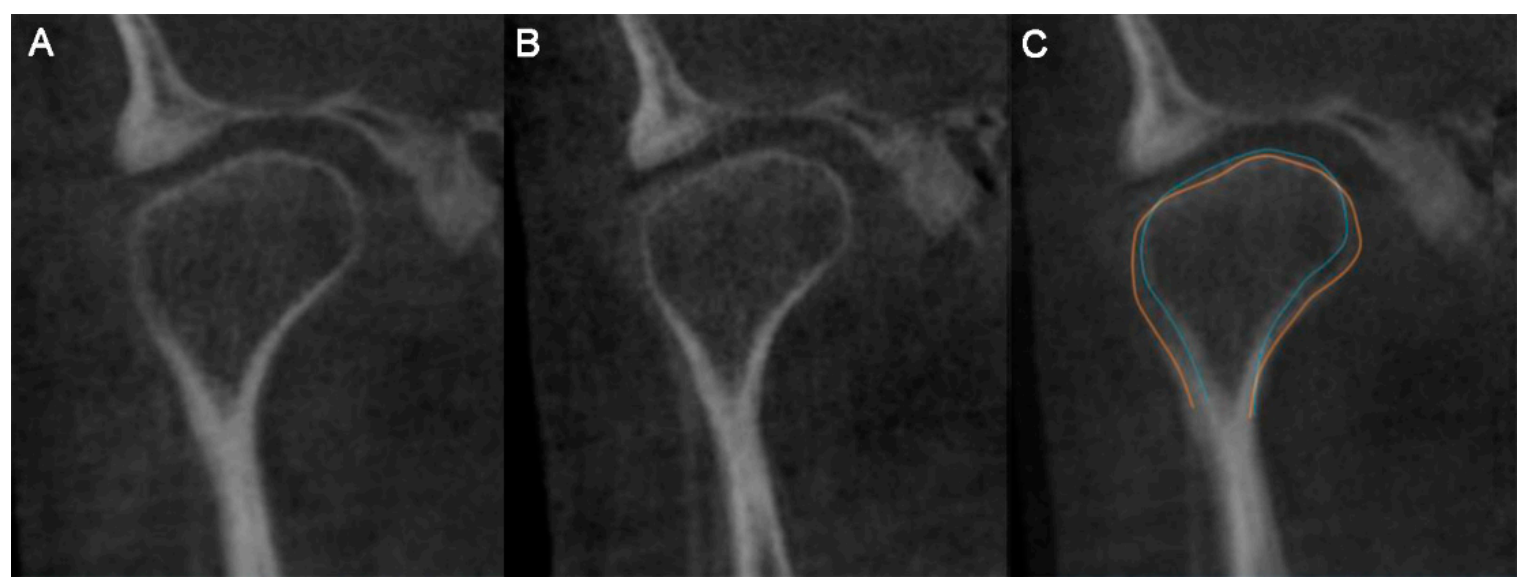

Figure 4. Overlapped radiographic images (CBCT; frontal view) of the pre-operative and post-operative natural side of the condyle. The image was selected at the largest dimension of the condyle in frontal plane. (A) Pre-operative radiograph on the natural side of the condyle. (B) Post-operative radiograph on the natural side of the condyle. (C) Overlapped image (pre-operative: orange line, post-operative: blue line).

\section{Discussion}

First of all, there are several limitations in this study. First, this paper is based on a small group of patients, which might be biased on concluding some of the results. Further larger group of cohort studies may needed for significant conclusions. In addition, the heterogeneity of the underlying diseases may inherently introduce a degree of bias into the results.

Conventional TMJ TJR procedures using autogenous materials, such as costochondral grafts, have been the gold standard for a long time. The benefits of using autologous graft materials involve its growth potential, biologic compatibility, and remodeling capacity. Thus, these procedures are expected in the treatment of TMJ ankylosis in young patients. Despite these merits, donor site morbidity and unpredictable growth have limited wider use of these grafts in other patients [3-6]. To overcome the problems of the conventional autologous graft, various alloplastic TMJ TJR systems were developed. However, those early type of TMJ TJR were unsuccessful as the Vitek or Kent prostheses appeared to have issues with various foreign body reactions and mechanical fragility [12]. Recent technological advances have made the alloplastic TMJ TJR materials and procedures more reliable and a feasible treatment option for restoring TMJ functions in non-salvageable TMJ conditions. Recently, the TMJ concept ${ }^{\circledR}$ (TMJ concepts Inc., Ventura, CA, USA) system and the Biomet Lorenz system have been popularized as standard systems representing customized and ready-made stock systems, respectively $[11,15,22,23,25,26]$.

Current alloplastic prosthesis systems in TMJ TJR have neither donor site morbidity, nor long-term temporary maxilla-mandibular fixation, reducing both operation time and hospitalization period. In addition, current TMJ TJR system offers the ability to correct facial asymmetry and early commencement of physical therapy for restoration of normal jaw function [27].

The TMJ concept ${ }^{\circledR}$ system as a 3D-printed customized alloplastic TMJ TJR system has many merits as compared to a ready-made one. It may be safer for the patient by the need for less bone removal and that it is easy to set the components in the physiologically appropriate position [28]. However, as our study showed, ready-made system also worked well without any major complications. Similarly, several studies comparing different TMJ replacement systems showed no relevant difference $[24,26]$. From an economic aspect, as patient-specific custom system is too expensive and the Korean national health care system currently supports only the ready-made system, the ready-made system is a more practical choice for Korean patients [13,29,30]. 
Besides the cost issue of the device, in terms of longevity of the prosthesis, potential wear debris could aggravate destructive tissue reactions and affect finite durability of the prosthesis. Based on orthopedic experience, the desired lifetime of such a device should be at least 20 years [27]. Some patients in this study concerns about another replacement surgery in the future because they are still young. Therefore, they are instructed to do more care about chewing and clenching to avoid wearing the alloplastic TMJ TJR. One of the disadvantages of the current alloplastic TMJ TJR system includes the limitation of condylar movement with limited translational and lateral movements [2]. The current designs of stock alloplastic systems require significant amount of bone removal to fit the prosthesis. Furthermore, because of the thickness of the fossa prosthesis, the center of hinge rotation moves inferiorly as compared with the natural TMJ and pseudotranslation of condylar prosthesis has occurred [31]. Lack of translational movements of condylar prosthesis is caused by the loss of lateral pterygoid muscle attachment and fibrotic scar tissue around the prostheses [31]. However, as our case series showed that average MMO was more than $40 \mathrm{~mm}$ and no chewing discomfort existed after surgery, limited translation movement after unilateral alloplastic TMJ TJR would not be matters for patient's quality of life.

In previous studies, post-operative MMO of alloplastic TMJ TJR was approximately $35 \mathrm{~mm}$ with translation constrained to less than $2 \mathrm{~mm}[15,28,32,33]$. In our study, the mean value of MMO was $44.1 \pm 6.9 \mathrm{~mm}$. It is mainly because the natural joint allows for an MMO as large as it can. Therefore, the opening path of the mandible after surgery a bit slanted towards the alloplastic side. Interestingly, the alloplastic condyle kept its articulation from the fossa prosthesis even in repeated measurements of MMO of approximately $40 \mathrm{~mm}$. It might be also because of less scar formation using minimally invasive approaches like a small incision and minimum surgical trauma in our cases. Several studies have discussed limited joint function due to excessive scar tissue after surgery [33-35]. Another possible reason for significant gain of $\mathrm{MMO}$ is our physiotherapy protocol. As mentioned earlier, our post-operative mouth opening exercise started as early as 5-7 days after surgery and was instructed to continue for life as a routine exercise in daily life. As a result, the amount of MMO become a plateau at about twelve months after surgery.

Lateral excursion movement of the mandible is important for grinding food and speaking. As the lateral pterygoid muscle should be detached at the alloplastic TMJ TJR side $[33,35]$, lateral excursion of the mandible to the operated side was limited. Further study should be necessary to recover this functional pitfall for better function of the mandible after alloplastic TMJ TJR.

In our eight cases of unilateral alloplastic TJR of the TMJ, all natural joints showed no functional disability at all. However, the shape of the condylar head of the natural condyles changed in all cases, which represents remodeling of the natural condylar structures as an adaptation to new mandibular movement physiology influenced by the alloplastic TJR system on the other side. Although longer observation periods are needed for the potential development of temporomandibular disorders on the natural side of the TMJ, it is quite promising that unilateral alloplastic TJR of TMJ was not detrimental to the natural side of TMJ.

Possible major complications of the alloplastic TJR of TMJ could involve massive bleeding, facial nerve palsy, inadequate placement of prosthesis, and post-operative infection. In our cases, we did not experience any of the above issues. However, massive bleeding during condylectomy has occurred in a bilateral alloplastic TMJ TJR case (data not shown). It was successfully managed with substantial gauze packing for about $20 \mathrm{~min}$ as its bleeding focus could not be clearly seen through the small endaural incision. In addition, perforation into the middle cranial fossa should also be avoided, because the ready-made system is a standardized product and all the surfaces in contact with the underlying bone are practically flat, so a considerable amount of bone reduction is necessary [36]. Thus, measurement of the thickness of the skull base to avoid perforation is important for a safe reduction of the glenoid fossa and articular eminence. 


\section{Conclusions}

In this study, we investigated unilateral alloplastic TMJ TJR with diverse clinical situations. Although our study might be biased and have limitations on concluding several results due to small size of patients, our cases showed stable and reliable clinical outcomes. And no adverse effects were observed on either the alloplastic TMJ TJR side or the healthy natural joint side. Therefore, unilateral alloplastic TMJ TJR might be a useful option if it is indicated for patients. In future procedures of alloplastic TMJ TJR, limited mandibular translation caused by morphometric characteristics of the current alloplastic systems should be improved to provide more natural and ideal mandibular movements.

Author Contributions: J.-H.K., B.-H.P., and M.-S.Y. analyzed the data, assisted surgery, wrote the manuscript. B.-K.L. conceived the study, performed surgery, analyzed the data and wrote the manuscript. All authors have read and agreed to the published version of the manuscript.

Funding: This research received no external funding.

Institutional Review Board Statement: The study was approved by the Institutional Review Board at Asan Medical Center (S2020-0684-0001).

Informed Consent Statement: Informed consent was obtained from all subjects involved in the study.

Data Availability Statement: The data that support the findings of this study are available from the corresponding author, $\mathrm{BKL}$, and the first author, JHK, upon reasonable request.

Conflicts of Interest: The authors declare no conflict of interest.

\section{References}

1. MacIntosh, R.B. The use of autogenous tissues for temporomandibular joint reconstruction. J. Oral Maxillofac. Surg. 2000, 58, 63-69. [CrossRef]

2. Jones, R. Temporomandibular joint reconstruction with total alloplastic joint replacement. Aust. Dent. J. 2011, 56, 85-91. [CrossRef]

3. Kaban, L.B.; Perrott, D.H.; Fisher, K. A protocol for management of temporomandibular joint ankylosis. J. Oral Maxillofac. Surg. 1990, 48, 1145-1151. [CrossRef]

4. Kaban, L.B.; Bouchard, C.; Troulis, M.J. A Protocol for Management of Temporomandibular Joint Ankylosis in Children. J. Oral Maxillofac. Surg. 2009, 67, 1966-1978. [CrossRef]

5. Cho, J.-W.; Park, J.-H.; Kim, J.-W.; Kim, S.-J. The sequential management of recurrent temporomandibular joint ankylosis in a growing child: A case report. Maxillofac. Plast. Reconstr. Surg. 2016, 38, 1-6. [CrossRef] [PubMed]

6. Jang, H.W.; Kim, N.-K.; Lee, W.-S.; Kim, H.J.; Cha, I.-H.; Nam, W. Mandibular condyle and infratemporal fossa reconstruction using vascularized costochondral and calvarial bone grafts. J. Korean Assoc. Oral Maxillofac. Surg. 2014, 40, 83-86. [CrossRef]

7. Carr, A.J.; Robertsson, O.; Graves, S.; Price, A.J.; Arden, N.K.; Judge, A.; Beard, D.J. Knee replacement. Lancet 2012, 379, 1331-1340. [CrossRef]

8. Kim, H.-A.; Kim, S.; Seo, Y.I.; Choi, H.J; Seong, S.-C.; Song, Y.W.; Hunter, D.; Zhang, Y. The epidemiology of total knee replacement in South Korea: National registry data. Rheumatology 2008, 47, 88-91. [CrossRef]

9. Hawkins, A.; Mercuri, L.G.; Miloro, M. Are Rib Grafts Still Used for Temporomandibular Joint Reconstruction? J. Oral Maxillofac. Surg. 2020, 78, 195-202. [CrossRef] [PubMed]

10. Mercuri, L. Alloplastic temporomandibular joint replacement: Rationale for the use of custom devices. Int. J. Oral Maxillofac. Surg. 2012, 41, 1033-1040. [CrossRef] [PubMed]

11. Lee, W.-Y.; Park, Y.-W.; Kim, S.-G. Comparison of Costochondral Graft and Customized Total Joint Reconstruction for Treatments of Temporomandibular Joint Replacement. Maxillofac. Plast. Reconstr. Surg. 2014, 36, 135-139. [CrossRef]

12. Kent, J.N.; Block, M.S.; Halpern, J.; Fontenot, M.G. Update on the Vitek partial and total temporomandibular joint systems. J. Oral Maxillofac. Surg. 1993, 51, 408-415. [CrossRef]

13. Lee, S.-H.; Ryu, D.-J.; Kim, H.-S.; Kim, H.-G.; Huh, J.-K. Alloplastic total temporomandibular joint replacement using stock prosthesis: A one-year follow-up report of two cases. J. Korean Assoc. Oral Maxillofac. Surg. 2013, 39, 297-303. [CrossRef]

14. Mercuri, L.G. Patient-Fitted ("Custom”) Alloplastic Temporomandibular Joint Replacement Technique. Atlas Oral Maxillofac. Surg. Clin. 2011, 19, 233-242. [CrossRef] [PubMed]

15. Wolford, L.; Movahed, R.; Teschke, M.; Fimmers, R.; Havard, D.; Schneiderman, E. Temporomandibular Joint Ankylosis Can Be Successfully Treated With TMJ Concepts Patient-Fitted Total Joint Prosthesis and Autogenous Fat Grafts. J. Oral Maxillofac. Surg. 2016, 74, 1215-1227. [CrossRef] [PubMed]

16. De Meurechy, N.; Mommaerts, M. Alloplastic temporomandibular joint replacement systems: A systematic review of their history. Int. J. Oral Maxillofac. Surg. 2018, 47, 743-754. [CrossRef] [PubMed] 
17. Mercuri, L.G.; Wolford, L.M.; Sanders, B.; White, R.; Giobbie-Hurder, A. Long-term follow-up of the CAD/CAM patient fitted total temporomandibular joint reconstruction system. J. Oral Maxillofac. Surg. 2002, 60, 1440-1448. [CrossRef]

18. Franco, P.; Talwar, R.; Wolford, L. Unilateral TMJ total joint reconstruction and the effects on the contralateral joint. AAOMS 79th Annual Meeting and Scientific Sessions. J Oral Maxillofac. Surg. 1997, 55, 113.

19. Perez, D.E.; Wolford, L.M.; Schneiderman, E.; Movahed, R.; Bourland, C.; Gutierrez, E.P. Does Unilateral Temporomandibular Total Joint Reconstruction Result in Contralateral Joint Pain and Dysfunction? J. Oral Maxillofac. Surg. 2016, 74, $1539-1547$. [CrossRef]

20. Bekcioglu, B.; Bulut, E.; Bas, B. The Effects of Unilateral Alloplastic Temporomandibular Joint Replacement on the Opposite-Side Natural Joint: A Finite-Element Analysis. J. Oral Maxillofac. Surg. 2017, 75, 2316-2322. [CrossRef]

21. Granquist, E.J.; Quinn, P.D. Total Reconstruction of the Temporomandibular Joint with a Stock Prosthesis. Atlas Oral Maxillofac. Surg. Clin. 2011, 19, 221-232. [CrossRef]

22. Aagaard, E.; Thygesen, T. A prospective, single-centre study on patient outcomes following temporomandibular joint replacement using a custom-made Biomet TMJ prosthesis. Int. J. Oral Maxillofac. Surg. 2014, 43, 1229-1235. [CrossRef]

23. Leandro, L.L.; Ono, H.; Loureiro, C.D.S.; Marinho, K.; Guevara, H.G. A ten-year experience and follow-up of three hundred patients fitted with the Biomet/Lorenz Microfixation TMJ replacement system. Int. J. Oral Maxillofac. Surg. 2013, 42, 1007-1013. [CrossRef] [PubMed]

24. Siegmund, B.; Winter, K.; Meyer-Marcotty, P.; Rustemeyer, J. Reconstruction of the temporomandibular joint: A comparison between prefabricated and customized alloplastic prosthetic total joint systems. Int. J. Oral Maxillofac. Surg. 2019, 48, 1066-1071. [CrossRef] [PubMed]

25. Gerbino, G.; Zavattero, E.; Bosco, G.; Berrone, S.; Ramieri, G. Temporomandibular joint reconstruction with stock and custommade devices: Indications and results of a 14-year experience. J. Cranio Maxillofac. Surg. 2017, 45, 1710-1715. [CrossRef]

26. Zou, L.; He, D.; Ellis, E. A Comparison of Clinical Follow-Up of Different Total Temporomandibular Joint Replacement Prostheses: A Systematic Review and Meta-Analysis. J. Oral Maxillofac. Surg. 2018, 76, 294-303. [CrossRef] [PubMed]

27. Giannakopoulos, H.E.; Sinn, D.P.; Quinn, P.D. Biomet Microfixation Temporomandibular Joint Replacement System: A 3-Year Follow-Up Study of Patients Treated During 1995 to 2005. J. Oral Maxillofac. Surg. 2012, 70, 787-794. [CrossRef]

28. De Meurechy, N.K.G.; Zaror, C.E.; Mommaerts, M.Y. Total Temporomandibular Joint Replacement: Stick to Stock or Optimization by Customization? Craniomaxillofacial Trauma Reconstr. 2020, 13, 59-70. [CrossRef]

29. Rhee, S.-H.; Baek, S.-H.; Park, S.-H.; Kim, J.-C.; Jeong, C.-G.; Choi, J.-Y. Total joint reconstruction using computer-assisted surgery with stock prostheses for a patient with bilateral TMJ ankylosis. Maxillofac. Plast. Reconstr. Surg. 2019, 41, 1-6. [CrossRef]

30. Park, J.-H.; Jo, E.; Cho, H.; Kim, H.J. Temporomandibular joint reconstruction with alloplastic prosthesis: The outcomes of four cases. Maxillofac. Plast. Reconstr. Surg. 2017, 39, 6. [CrossRef]

31. Van Loon, J.-P.; Falkenstrom, C.H.; De Bont, L.G.M.; Verkerke, G.J.; Stegenga, B. The Theoretical Optimal Center of Rotation for a Temporomandibular Joint Prosthesis: A Three-dimensional Kinematic Study. J. Dent. Res. 1999, 78, 43-48. [CrossRef]

32. Kanatsios, S.; Breik, O.; Dimitroulis, G. Biomet stock temporomandibular joint prosthesis: Long-term outcomes of the use of titanium condyles secured with four or five condylar fixation screws. J. Cranio Maxillofac. Surg. 2018, 46, 1697-1702. [CrossRef]

33. Wojczyńska, A.; Leiggener, C.; Bredell, M.; Ettlin, D.; Erni, S.; Gallo, L.; Colombo, V. Alloplastic total temporomandibular joint replacements: Do they perform like natural joints? Prospective cohort study with a historical control. Int. J. Oral Maxillofac. Surg. 2016, 45, 1213-1221. [CrossRef] [PubMed]

34. Westermark, A.; Leiggener, C.; Aagaard, E.; Lindskog, S. Histological findings in soft tissues around temporomandibular joint prostheses after up to eight years of function. Int. J. Oral Maxillofac. Surg. 2011, 40, 18-25. [CrossRef]

35. Mercuri, L.G. Subjective and objective outcomes in patients reconstructed with a custom-fitted alloplastic temporomandibular joint prothesis. J. Oral Maxillofac. Surg. 1999, 57, 1427-1430. [CrossRef]

36. Bai, G.; He, D.; Yang, C.; Chen, M.; Yuan, J.; Wilson, J.J. Application of Digital Templates to Guide Total Alloplastic Joint Replacement Surgery With Biomet Standard Replacement System. J. Oral Maxillofac. Surg. 2014, 72, 2440-2452. [CrossRef] [PubMed] 